\title{
Post-Traumatic Stress Disorder among Burn Patients in a Tertiary Hospital
}

\author{
Hasan $\mathrm{MI}^{1}$, Rahman $\mathrm{MS}^{2}$, Shaheen $\mathrm{R}^{3}$
}

DOI: https://doi.org/10.3329/jafmc.v15i1.48636

\begin{abstract}
Introduction: Imbalance in multi-factorial components of human ecology plays a role in developing post-traumatic stress disorder hampering economical productivity and normal social life.
\end{abstract}

Objectives: To find out the interplay of issues that are conducive to the outcome of the disorder among hospital admitted burn patients.

\begin{abstract}
Materials and Methods: This unobtrusive qualitative behavioral health research by in-depth interview was conducted among conveniently selected 35 burn patients in Dhaka Medical College Hospital of Bangladesh from July 2013 to June 2014. The data were analyzed to draw conclusion through etic and/or emic interpretation. All ethical issues were taken care of.
\end{abstract}

Results: The highest $80 \%$ burn patients were married, $71 \%$ were male, and $80 \%$ were Muslim. Majority $37.14 \%$ were day laborer, $28.57 \%$ had completed primary education, $34.29 \%$ belonged to the age group $21-30$ years, and $43 \%$ had monthly family income up to Tk. 10000 . Of $41 \%$ burn occurring at home, majority $27 \%$ occurred during rice cooking, affecting the upper limb in $29 \%$ cases. Social dislocation was the major phenomena leading to burn injury in $22.86 \%$ of the patients. Lack of harmonious relationship and in-laws poking in conjugal life sometime led to deliberate infliction of burn.

Conclusion: The study concluded with the suggestions for prevention of neoteric entry in the domain of post-traumatic stress disorder through social movement and psychotherapy of burn patients. Study also hinted for further probing of the phenomenon of the disorder.

Key-words: Post-traumatic stress disorder, Burn patients, Bangladesh

\section{Introduction}

The emotional response to an appalling event like accident, burn, rape or disaster is usually followed by shock and denial. Longer term reactions include unpredictable emotions, flashbacks, strained relationships, and even physical symptoms. Some people have difficulty in coping with these feeling leading to posttraumatic stress disorder (PTSD), while other take it in their stride and move on. Psychologists have given emphasis on twelve sequential steps for development of PTSD ${ }^{1}$. These are activating event, pain, confusion, guilt, shame, self-worth dissipating, anxiety, fear, anger, resentment, depression, and acute anxiety. The first seven of these steps collectively represent pre-PTSD phase. The eighth step is PTSD formation phase, and the rest are called post-PTSD phase. Up to $30 \%$ of people experiencing a traumatic event may develop PTSD. An estimated $10 \%$ of women and $5 \%$ of men experience PTSD at some point in their life in any society. The risk for developing PTSD varies greatly with different kinds of trauma. People with PTSD may not present for treatment for months or years after onset of symptoms. Psychologists can help the PTSD cases to find positive ways to manage their emotions ${ }^{2}$. Burns are a leading cause of disability and disfigurement. It is estimated that fire-related burns account for 10 million Disability Adjusted Life Years lost globally each year ${ }^{3}$. Burn injuries are among the most common distressing injuries that pose a major public health problem. Globally, burns are the fourth most common type of trauma, following traffic accidents, falls, and interpersonal violence. About 90.00 percent of burns occur in developing countries, that is, regions that generally lack the necessary infrastructure to reduce the incidence and severity of burns ${ }^{4}$. Burn is a life threatening state that challenges all of the main integrating systems of the body. Survival rates after burns have increased in recent decades as surgical techniques and treatments have improved ${ }^{5}$. As more burn patients survive, the potential psychological morbidity has also increased. Although many patients with burn recover well and have a satisfying quality of life after the trauma, some patients experience persistent psychological symptoms specially $\mathrm{PTSD}^{6}$.

Bangladesh is a developing country in South Asia, where the social context of the country is male dominant. Psychosocial trauma due to deliberate accidental phenomenon in general and burn in particular is not uncommon ${ }^{7}$. There is very few research or published literature on the psychological aspects of burns in Bangladesh. A driving force behind this study has been the intention to explore factors influencing outcome beyond the sophisticated medical and surgical reconstructions, and physical exercises along with the pre-burn factors contributing to the occurrence of PTSD. So the research questions arise whether there are any psychosocial trauma among burn patients; if so, what are the interplaying psychosocial traumatic phenomena, whether the trauma are propelling the patients towards PTSD among burn patients admitted in Dhaka Medical College Hospital (DMCH). This study has been done in a limited scale within a specific health facility, yet the study findings have some limited generalizability, as the socio-cultural make-up on the issue appears fairly uniform across the country. The study did not include burn patients who refused to give consent, or were unable to communicate because of severe burn.

\section{Materials and Methods}

This empirical, descriptive, qualitative, reactive (unobtrusive) study employed tools of health behavioral sciences to collect data from inpatient of Burn and Plastic Surgery Department of DMCH, Bangladesh from July 2013 to June 2014. Data on the psychosocial

1. Brig Gen Md Iqbal Hasan, MBBS, MPH, MDM, MPhil, Trainee Officer, AFMI, Dhaka (E-mail: iq683@yahoo.com) 2. Dr Md Shafiqur Rahman, MBBS, MPH, PhD, Associate Professor \& Head, Department of Community Medicine, Army Medical College, Jashore, Bangladesh 3. Dr Rukhsana Shaheen, MBBS, MPH, PhD, Assistant Professor of Community Medicine Shaheed Tajuddin Ahmed Medical College, Gazipur, Bangladesh. 
phenomena among burn patients through recall were collected. In-depth interviews with the patients were done in the morning after routine round of the burn ward by the chief physician of the Department so that the normal activities of the Department were not disturbed. Bearing in mind all round situations, it was possible to conveniently pick-up 35 samples. As the circumstances permit and requirements demand, etic and/or emic interpretation were done to elucidate the information generated on analysis of data. After explaining the study objectives, potential comfort/ discomfort, informed verbal consent was taken from data sources. They were free to retract their consent at any stage of their participation. Anonymity and confidentiality of the subjects were maintained. No coercion or deception was done. No physical, chemical, psychosocial, or biological intervention was given to study subjects. Plagiarism in any form has been avoided by duly acknowledging, citing and referencing, and other issues related to documentation.

\section{Results}

The study revealed $71.43 \%$ of the patients were male and the rest $28.57 \%$ were female. About $80 \%$ were Muslim and the rest $20 \%$ were Hindu. It was found that $22.86 \%$ of the patients were in the age group $10-20$ years and $34.29 \%$ in age group $21-30$ years. The remaining $25.71 \%, 14.29 \%$ and $2.86 \%$ patients were in age groups of 31-40 years, $41-50$ years and $51-60$ years respectively. Majority $28.57 \%$ of the patient completed primary education. The remaining $17.14 \%$ were illiterate, $22.86 \%$ had completed secondary education, $17.14 \%$ had completed higher secondary education, and $14.29 \%$ had completed graduation. Most $37.14 \%$ of the burn patients were day laborer, whereas $28.57 \%, 17.14 \%$, $11.43 \%$, and $5.71 \%$ were homemaker, student, service holder, and businessperson respectively. Among the burn patients, highest $42.86 \%$ had monthly family income up to Taka 10000 . Least number of people about $5.71 \%$ had monthly family income of Taka 31000 and above. Remaining $34.29 \%$ and $17.14 \%$ had monthly family income within Taka 11000-20000 and Taka 2100030000 respectively. About $80 \%$ of the burn patients in this study were married and the rest $20 \%$ were unmarried (Table-I).

About $42.85 \%$ burn occurred at home, $28.57 \%$ at workplace, $17.14 \%$ from electric pole, and $5.71 \%$ at other location of accidents. Most of the burn cases occurred at home through rice cooking pot, which was $26.67 \%$ and accidental fall $26.67 \%$. Remaining were water-boiling pot $13.33 \%$, any hot pot $13.33 \%$, clothing $13.33 \%$ and others $6.67 \%$. Upper limb was involved in $22.86 \%$ cases, front of the trunk $25.71 \%$, head neck and face $28.57 \%$, lower limb $11.42 \%$, back of the trunk $8.57 \%$ and perineum $2.87 \%$. Social dislocation was the major phenomena leading to burn injury in $22.86 \%$ of the patients. Dowry, illicit relationship, enmity and accidental phenomena were $17 \pm 14 \%$, $14 \pm 28 \%, 8 \pm 57 \%$ and $20 \%$ respectively. The phenomena 'others' was $17 \pm 14 \%$ (Table-II).

In 'fear phase', the forming phase of PTSD, there were $14.28 \%$ burn patients. There were $5.71 \%$ in anger and $2.85 \%$ in depression steps, while none of the patients were in 'resentment' or 'acute anxiety' steps of post-PTSD phase. Most of the burned patients in initial days of burn fall in the steps prior to 'fear step' or PTSD formation phase. They were $22.85 \%, 14.28 \%, 11.48 \%$, $8.57 \%$ and $20 \%$ percent in anxiety, shame, guilt, confusion and pain steps respectively. None were in 'self-worth dissipating' and 'activating event' steps. Most of the patients were managed by both medical and surgical procedures; only medical treatment was given to $31.43 \%$, only surgical to $11.43 \%$, while combined medical and surgical treatments were given to $57.14 \%$ patients. None of the patients were given psychological therapy (Table-III).

Table-l: Socio-demographic characteristics of burn patients $(n=35)$

\begin{tabular}{|c|c|c|c|}
\hline \multicolumn{2}{|c|}{ Characteristics } & Frequency & Percentage \\
\hline \multirow{5}{*}{ Age in years } & $10-20$ & 8 & 22.86 \\
\hline & $21-30$ & 12 & 34.29 \\
\hline & $31-40$ & 9 & 25.71 \\
\hline & $41-50$ & 5 & 14.29 \\
\hline & $51-60$ & 1 & 2.86 \\
\hline \multirow{2}{*}{ Sex } & Male & 25 & 71.43 \\
\hline & Female & 10 & 28.57 \\
\hline \multirow{2}{*}{ Religion } & Islam & 28 & 80.00 \\
\hline & Hinduism & 7 & 20.00 \\
\hline \multirow{5}{*}{ Education } & Illiterate & 6 & 17.14 \\
\hline & Primary & 10 & 28.57 \\
\hline & \begin{tabular}{|l|} 
Secondary \\
\end{tabular} & 8 & 22.86 \\
\hline & Higher secondary & 6 & 17.14 \\
\hline & Graduation & 5 & 14.29 \\
\hline \multirow{5}{*}{ Occupation } & Student & 6 & 17.14 \\
\hline & Service & 4 & 11.43 \\
\hline & Business & 2 & 5.71 \\
\hline & Housewives & 10 & 28.57 \\
\hline & Day laborer & 13 & 37.14 \\
\hline \multirow{2}{*}{ Marital status } & Married & 28 & 80.00 \\
\hline & \begin{tabular}{|l|} 
Unmarried \\
\end{tabular} & 7 & 20.00 \\
\hline \multirow{4}{*}{ Monthly family income (Taka) } & $\leq 10000$ & 15 & 42.86 \\
\hline & $11000-20000$ & 12 & 34.29 \\
\hline & $21000-30000$ & 6 & 17.14 \\
\hline & $\geq 31000$ & 2 & 5.71 \\
\hline
\end{tabular}

Table-II: Burn related information of patients $(n=35)$

\begin{tabular}{|c|c|c|c|}
\hline \multicolumn{2}{|c|}{ Characteristics } & Frequency & Percentage \\
\hline \multirow{5}{*}{$\begin{array}{l}\text { Place of } \\
\text { occurrence }\end{array}$} & Home & 15 & 42.85 \\
\hline & Workplace & 10 & 28.57 \\
\hline & Electric pole & 6 & 17.14 \\
\hline & Accidental & 2 & 5.71 \\
\hline & Others & 2 & 5.71 \\
\hline \multirow{6}{*}{$\begin{array}{l}\text { Causes of burn at } \\
\text { home }\end{array}$} & Rice cooking pot & 4 & 26.67 \\
\hline & Water boiling pot & 2 & 13.33 \\
\hline & Any hot pot & 2 & 13.33 \\
\hline & Accidental fall & 4 & 26.67 \\
\hline & Clothing & 2 & 13.33 \\
\hline & \begin{tabular}{|l|} 
Others \\
\end{tabular} & 1 & 6.67 \\
\hline \multirow{6}{*}{ Body area burned } & Head, neck, face & 8 & 22.86 \\
\hline & Front of trunk & 9 & 25.71 \\
\hline & Back of trunk & 3 & 8.57 \\
\hline & Upper limb & 10 & 28.57 \\
\hline & Lower limb & 4 & 11.42 \\
\hline & Perineum & 1 & 2.87 \\
\hline \multirow{6}{*}{$\begin{array}{l}\text { Phenomenon of } \\
\text { burn }\end{array}$} & Social dislocation & 08 & 22286 \\
\hline & \begin{tabular}{|l|} 
Dowry \\
\end{tabular} & 06 & $17 \square 14$ \\
\hline & Illicit relationship & 05 & $14 \square 28$ \\
\hline & Enmity & 03 & $08 \square 57$ \\
\hline & Accidental & 07 & $20 \square 00$ \\
\hline & \begin{tabular}{|l|} 
Others \\
\end{tabular} & 06 & $17 \square 14$ \\
\hline \multirow{4}{*}{$\begin{array}{l}\text { Mode of treatment } \\
\text { of burn patient }\end{array}$} & Medical only & 11 & 31.43 \\
\hline & Surgical only & 04 & 11.43 \\
\hline & Both surgical and medical & 20 & 57.14 \\
\hline & Psychological & 00 & 00.00 \\
\hline
\end{tabular}


Table-III: Phases of PTSD

\begin{tabular}{|l|c|c|}
\hline \multicolumn{1}{|c|}{ Phases of PTSD } & Frequency & Percentage \\
\hline Acute anxiety & 00 & 00.00 \\
\hline Depression & 01 & 02.85 \\
\hline Resentment & 00 & 00.00 \\
\hline Anger & 02 & 05.71 \\
\hline Fear & 05 & 14.28 \\
\hline Anxiety & 08 & 22.85 \\
\hline Self-worth dissipating & 00 & 00.00 \\
\hline Shame & 05 & 14.28 \\
\hline Guilt & 04 & 11.48 \\
\hline Confusion & 03 & 08.57 \\
\hline Pain & 07 & 20.00 \\
\hline Activating event(s) & 00 & 00.00 \\
\hline \multicolumn{1}{|c|}{ Total } & 35 & 100.00 \\
\hline
\end{tabular}

\section{Discussion}

This study revealed that $71.43 \%$ of the patients were male and the rest $28.57 \%$ were female. A higher rate of burn affected female patients was found in Kuwait, Iran and India. A study by Sadeghi-Bazargani et al describes a situation where $52 \%$ of the burn patients were female ${ }^{8}$. The tendency for men to report better perceived health status as compared to women has been found in several studies ${ }^{9}$. In Bangladesh, the scenario is reverse. The more male patients in the hospital maybe related to their social domination and privileged roles. Males are probably more vulnerable to burn because of their occupation, but females sustain more severe burn. Most of the burn patients admitted in $\mathrm{DMCH}$ were in the age group 21-30 years, which was consistent with most other studies, although age grouping was different in different studies ${ }^{10}$. For example in the study by Ansari et al in Iran, the 15-64 years old age group was more at risk ${ }^{11}$, while in the study by Rastegar et al children under 5 years old were mostly burned ${ }^{12}$. Another study in Iran by Homayon-Sadeghi et al reported that the burn patients were more in age group 30-40 years ${ }^{13}$. Incidence is higher in this study, perhaps due to early exposure at work place without safety measures. As age increases, the occurrence of burn decreases and becomes almost negligible above 50 years of age. Among 35 of the burn patients $80 \%$ were Muslim and the rest $20 \%$ were Hindu. Bangladesh is a Muslim dominant country, which is reflected in this study. This study revealed that the majority $28.57 \%$ of the patient completed primary education. The remaining $17.14 \%$ were illiterate, $22.86 \%$ had completed secondary education, $17.14 \%$ had completed higher secondary education, and $14.29 \%$ had completed graduation. According to The Department of Accident and Emergency Medicine, Northern General Hospital in Egypt the low educational status is one of the major factors contributing to burn injury ${ }^{14}$. Like other developing country educational level of the burn patient in this study was also low. Illiteracy and lower educational levels of people make them less aware of the safety related issues. The study revealed that most of the burn patients were day laborer, which was $37.14 \%$. Whereas $28.57 \%, 17.14 \%, 11.43 \%$ and $5.71 \%$ were homemaker, student, service holder and businessperson respectively. In another study, it was seen that highest rate of burn was observed in the manufacturing sector for male day laborer. Welders, cooks, food service workers, and mechanics had higher occurrence of burn injury compared with other occupations ${ }^{15}$. In another study in Iran, most of the burn patients were homemakers ${ }^{16}$. Some of the other studies showed similar results as found in this study. Male day laborers are probably more involved in risky jobs where there is possibility of burn, while female are more at risk because the fuel used for household jobs is handled in unsafe way. Among the burn patients, highest $42.86 \%$ had monthly family income up to Taka10000. Least number of people about $5.71 \%$ had monthly family income of Taka 31000 and above. Remaining $34.29 \%$ and $17.14 \%$ had monthly family income within Taka $11000-20000$ and Taka 21000-30000 respectively. According to The Department of Accident and Emergency Medicine, Northern General Hospital of Egypt, the low socioeconomic condition is one of the major factors contributing to burn injury ${ }^{17}$. Poverty causes family members to involve in the job with risk, and causes family disharmony and depression pushing people to self-inflicted burn. The highest $80 \%$ of the burn patients in this study were married and the rest $20 \%$ of the patients were unmarried. Married couples have more responsibility to maintain family life, run the kitchen, and involve in risky job maybe the reason of higher occurrence of burn.

Maximum $42.85 \%$ place of occurrence of burn was at home. Remaining $28.57 \%$ in workplace, $17.14 \%$ from electric pole and $5.71 \%$ at other location of accidents. With respect to the place where the burn injury occurred, the majority $91.4 \%$ of burns occurred in home as revealed by studies in several developing countries $^{18-20}$. Careless use of natural gas in cooking, faulty wiring in electric line, self inflicted or dowry related burn usually occurred at home and maybe the reason for more burn cases occurring in home in Bangladesh. Most of the burn cases admitted in $\mathrm{DMCH}$ occurred at home through rice cooking pot, which was $26.67 \%$ and accidental fall $26.67 \%$. Remaining were water-boiling pot $13.13 \%$, any hot pot $13.13 \%$, clothing $13.13 \%$ and others $6.67 \%$. A study in Egypt found that most burns were accidental. In the causes of burn injury, flame was the most common agent affecting more than two-thirds of cases, followed by electrical, scald and chemical burns. As regards the source of flame, portable pressure kerosene stoves were the most common source and were responsible for slightly more than half the cases $^{21}$. This is consistent with the findings of previous studies in developing countries ${ }^{22}$. On the other hand, the picture reported from industrialized countries differs, where flammable liquids and gas stoves were the most common source of flame burns ${ }^{23}$. Burn agents are highly individualized in each country, largely depending on the standard of living and lifestyle. The reason for more burn cases in Bangladesh maybe related to casual use of rice cooking pot for cooking by the females where they are not much more sensitized towards proper handling of the pot, and thus casualty of burn accident. Among the burn patients admitted in the Burn and Plastic Surgery Department of DMCH, upper limb involved $28.57 \%$, front of the trunk $25.71 \%$, head-neck and face $22.86 \%$, lower limb $11.42 \%$, back of the trunk $8.57 \%$ and perineum $2.87 \%$. In a study in Iran, most burns occur in the upper part of the body. Facial burns are more common in flame burns and upper limbs are injured mostly due to electric burn. Wrist and hand burns 
accounted for a majority of burn injuries ${ }^{24}$. The finding of this study corroborates with the finding of the study in Iran as regards to the most common part of the body affected with burn. This is likelihood of common ergonomics of household appliances used by females as well as their interest in manual cooking habit. Social dislocation was the major phenomena leading to burn injury in $22.86 \%$ of the patients. Dowry, illicit relationship, enmity and accidental phenomena were $17 \pm 14 \%, 14 \pm 28 \%, 8 \pm 57 \%$ and $20 \%$ respectively. Most common phenomenon related to burn reveals social dislocation, which in all likelihood, hampers the usual setup of living including cooking place. The makeshift arrangement in cooking in different places may not be tuned with the person responsible for cooking. The change of cooking place may propel to accidental burn.

In 'fear step' or PTSD formation phase, there were $14.28 \%$ burn patients. About $5.71 \%$ were in 'anger' and $2.85 \%$ in 'depression' steps. None of the patients were in 'resentment' or 'acute anxiety' steps of post-PTSD phase. Most of the burned patients in initial days of burn fall in the steps prior to PTSD formation phase. They were $22.85 \%, 14.28 \%, 48 \%, 8.57 \%$ and $20 \%$ in anxiety, shame, guilt, confusion and pain steps respectively. None were in 'self-worth dissipating' and 'activating event' steps of pre-PTSD phase. It seems that due to less pre-burn trauma, patients admitted in hospital with burn take little time or window period to develop PTSD. Only few reach in the PTSD form at the very initial period of burn maybe due to previous trauma. This suggests that further longitudinal extended study is needed to better understand the possibility of the occurrence of PTSD in Bangladesh. Most of the burn patients, admitted in $\mathrm{DMCH}$ were managed by both medical and surgical procedures. Only medical treatment was given to $31.43 \%$ burn patients. Surgical treatment only was given to $11.43 \%$ burn patient, while both combined medical and surgical treatments were given to $57.14 \%$ patients. None of the patients was given psychological support in any stages of the treatment in hospital. The majority of the previous studies have focused on burn related factors, demographic factors and previous psychiatric history rather than psychological factors ${ }^{25}$. After a trauma the mode of treatment plays an important role in the recovery of the patient both physically and psychologically. The study reveals that priority was given towards physical improvement of the burn patients' treatment while psychological support was totally overlooked. This once again emphasizes that psychological support could contribute greatly to prevent PTSD among burn patients. Social mobilization to sensitize burn patients for psychological coping of trauma may be initiated in the country.

\section{Conclusion}

Interplay of complex human ecology contributes to the occurrence of post-traumatic stress disorder. Some predisposing factors come into play before the disorder develops. Interrupting the chain or breaking the complex may prevent the symptoms of post-traumatic stress disorder. The study recommends social movement to create a congenial human ecology that prevents development of the disorder. For those who have sustained burn, arrangement for dispensing psychological management alongside medical and surgical treatments need to be encouraged. Further studies over extended period encompassing pre- and post-traumatic events may be able to give a clearer picture of the situation of post-traumatic stress disorder among Bangladeshi people.

\section{References}

1. Hosier D. Hartman's 12 stages of post-traumatic stress disorder (PTSD). Childhood Trauma recovery, 2016. Available at: https:// childhoodtraumarecovery.com/complex-ptsd-articles/hartmans-12stages-post-traumatic-stress-disorder-ptsd/. Accessed 11 July 2018.

2. Emery RE. Post-traumatic Stress Disorder (PTSD). Encyclopedia Britannica, 2018. Available at: http://www.britannica.com/EBchecked/ topic/472284/post-traumatic-stress-disorder-PTSD. Accessed 27 November 2018.

3. Dalal PK, Shaha R, Agarwal M. Psychological aspects of burn. Indian J Plast Surg 2010; 43:S136-S142.

4. Kestler A, Sebego M, Roberts $M$ et al. The global burden of injuries. Am J Public Health, 2000. Available at: http://www.cugh.org/sites/default/ files/content/resources/modules/To\%20Post $\% 20$ Both $\% 20$ Faculty $\% 20$ and\%20Trainees/32_Global_Burden_of_Injuries_FINAL.pdf. Accessed 21 June 2018.

5. Klein MB, Lezotte DL, Fauerbach JA et al. The National Institute on Disability and Rehabilitation Research burn model system database: a tool for the multicenter study of the outcome of burn injury. J Burn Care Res 2007; 28(1):84-96.

6. Moi AL, Wentzel-Larsen T, Salemark L et al. Impaired generic health status but perception of good quality of life in survivors of burn injury. J Trauma 2006; 61(4):961-8. Available at: http://www.ncbi.nlm.nih.gov/ pubmed/17033569. Accessed 03 May 2018.

7. Solomon Z, Mikulincer M, Flum H. The implications of life events and social integration in the course of combat-related post-traumatic stress disorder. Soc Psychiatry Psychiatr Epidemiol 1989; 24(1):41-8.

8. Gardner PJ, Knittel-Keren D, Gomez M. The Post-traumatic Stress Disorder Checklist as a screening measure for Post-traumatic stress disorder in rehabilitation after burn injuries. Arc Phys Med Rehabil, 2012; 93(4):623-8. Available at: http://www.ncbi.nlm.nih.gov/ pubmed/22365477. Accessed 30 June 2018.

9. Brown B, Roberts J, Browne G et al. Gender differences in variables associated with psychosocial adjustment to a burn injury. Res Nurs Health, 1988; 11(1):23-30.

10. Panjeshahin MR, Lari AR, Talei A et al. Epidemiology and mortality of burns in the South West of Iran. Burns 2001; 27(3):219-26.

11. Ansari-Lari M, Askarian M. Epidemiology of burns presenting to an emergency department in Shiraz, South Iran. Burns 2003; 29(6):579-81.

12. Lari AR, Alaghehbandan R, Nikui $R$ et al. Epidemiological study of 3341 burns patients during three years in Tehran, Iran. Burns 2000; 26(1):49-53.

13. Sadeghi-Bazargani $H$, Maghsoudi $H$, Soudmand-Nuri $M$ et al. Stress disorder and PTSD after burn injuries: A prospective study of predictors of PTSD at Sina Burn Centre, Iran. Neuropsychiatr Dis Treat 2012; 7:425-9.

14. McKibben JB, Bresnick Mg, Wiechman Askey SA et al. Acute stress disorder and Post-traumatic stress disorder: A prospective study of 
prevalence, course, and predictors in a sample with major injuries. J Burn Care 2008; 29(1):22-35.

15. Islam SS, Nambiar AM, Doyle EJ et al. Epidemiology of work-related burn injuries: Experience of a state-managed workers' compensation system. J Trauma 2000; 49(6):1045-51.

16. Sadeghi-Bazargani $H$, Maghsoudi $H$, Soudmand-Nuri M et al. Stress disorder and PTSD after burn injuries: A prospective study of predictors of PTSD at Sina Burn Centre, Iran. Neuropsychiatr Dis Treat 2012; 7:425-9.

17. McKibben JB, Bresnick Mg, Wiechman Askey SA et al. Acute stress disorder and Post-traumatic stress disorder: A prospective study of prevalence, course, and predictors in a sample with major injuries. J Burn Care, 2008; 29(1):22-35.

18. Jaiswal AK, Aggarwal HA, Solanki P et al. Epidemiological and sociocultural study of burn patients in M. Y. Hospital, Indore, India. Indian Journal of Plastic Surgery 2007; 40(2):158-63.

19. Alam M, Ahmed R, Qayyum S et al. An epidemiological study of burn in Aligarh and adjacent areas. Surgery 2010; 20(25): 29-37.
20. Akther J M, Nerker N E, Reddy PS et al. Epidemiology of burned patients admitted in burn unit of a rural tertiary teaching hospital. Pravara Med Rev 2010; 2(4):11-17.

21. Ashraf MZ, Ahmed R, Butt MU et al. Psychosocial determinants of burn victims. Pakistan Journal of Medical \& Health Sciences, 2008; 2(3):78-84.

22. Jaiswal AK, Aggarwal HA, Solanki P et al. Epidemiological and sociocultural study of burn patients in M. Y. Hospital, Indore, India. Indian Journal of Plastic Surgery 2007; 40(2):158-63.

23. Pegg SP, McDonald GP, Tracey-Patte CE et al. Epidemiology of burns attending a casualty department in Brisbane. Burns Incl Therm In 1983; 9(6):416-21.

24. Islam SS, Nambiar AM, Doyle EJ et al. Epidemiology of work-related burn injuries: Experience of a state-managed workers' compensation. J Trauma 2000; 49(6):1045-51.

25. Joshephine ET, Tarrier N, Faragher EB. An investigation of the factors associated with an increased risk of psychological morbidity in burned injured patients. Burns 1998; 24(5):407-15. 